\title{
SEM-TERRA: OS SENTIDOS E AS TRANSFORMAÇÕES DE UMA CATEGORIA DE AÇÃO COLETIVA NO BRASIL*
}

Marcelo Carvalho Rosa

\section{Introdução}

Nos últimos 25 anos, sempre que mencionamos ou ouvimos a expressão "sem-terra" tendemos a associá-la a um movimento social, principalmente o Movimento dos Trabalhadores Rurais Sem Terra - MST. Tal relação constitui um senso comum que se espalha por meios de comunicação e que não reflete exatamente a gama de grupos organizados no Brasil que reivindicam a representação dessa categoria social ${ }^{1}$. Apesar disso, não podemos desconhecer que foi este movimento que consagrou a categoria social "sem-terra" como uma forma social de reconhecimento público ao ocupar não apenas fazendas consideradas improdutivas, mas também prédios e espaços públicos em quase todo o

\footnotetext{
* As pesquisas que deram origem a este artigo foram realizadas em um projeto conjunto com Lygia Sigaud e Marcelo Ernandez Macedo, aos quais agradeço pela troca de ideias e pelo apoio financeiro. Agradeço também a Bernard Alves e Isabel Palmeira, que trabalharam como bolsistas de iniciação científica em parte da pesquisa. As posições do artigo, no entanto, refletem minha própria elaboração em torno das ideias coletivas.

${ }^{1}$ Apenas para citar um exemplo, em 2003 havia apenas no estado de Pernambuco 14 movimentos distintos que organizavam ocupações de terra. Para mais informações sobre esses movimentos, ver Rosa (2004).
} 
país. A importância e o volume de suas ações contribuem para que o interesse sociológico acerca das suas formas de mobilização e de ação coletiva seja também vultoso. Trabalhos como os de Fernandes (2000), Navarro (1999 e 1996) e Chaves (2000) entre outros, dedicaram-se a desvendar um pouco desse mundo focalizando as tradições que lhe deram origem e as mudanças nas suas estratégias. Dentre esses trabalhos mais conhecidos não encontramos, no entanto, uma reflexão mais profunda sobre a relação entre o MST e a categoria de pessoas que representa: os "sem-terra". Para esses analistas, a emergência desse movimento foi o resultado político ou a expressão dos dilemas de um grupo social que, por razões históricas, encontravase sem a posse ou propriedade de terras nas quais pudessem subsistir ou reproduzir-se.

Neste artigo procuraremos centrar nossas preocupações justamente em um ponto que ainda tem sido pouco 198 trabalhado e, por vezes, naturalizado pela literatura que trata de analisar o MST: a própria categoria "sem-terra". A ideia de levar a cabo uma análise desse tipo surgiu de um investimento coletivo de pesquisa que tinha como objetivo compreender a emergência das ocupações como forma de reivindicar terras no Brasil das últimas décadas². Por meio dessa pesquisa, e até onde fomos capazes de explorar, chegamos aos primeiros momentos em que essa designação passou a ser usada para expressar "reivindicação" no Rio Grande do Sul na década de 1960. Ao longo do texto, procuraremos demonstrar que a expressão sem-terra surge no governo de Leonel Brizola (1959-1963), e dele se apropriam, modificando seu conceito, movimentos e organizações ao longo das décadas seguintes em regiões e situa-

\footnotetext{
${ }^{2}$ Uma visão geral dos resultados dessa pesquisa está publicada em Sigaud, Rosa e Macedo (2008). Preparamos para breve a publicação de um livro que apresentará estudos de casos sobre as ocupações no Rio de Janeiro, Pernambuco e Rio Grande do Sul.
} 
ções sociais bastante distintas, mas que tinham um sentido semelhante: orientar políticas de governo para pequenos agricultores. Nesse sentido, defenderemos a hipótese de que, no caso brasileiro, os "sem-terra" não existem como categoria autônoma em relação ao Estado. Ao final do artigo, procuraremos sucintamente mostrar como essa hipótese nos permite desenvolver argumentos para avançarmos nas trilhas das chamadas teorias dos processos e das oportunidades políticas.

\section{Sem-Terra nas vésperas do golpe}

O início dos anos sessenta mostra-se como um período crucial para pensarmos questões relativas ao binômio terra e política no Brasil. Naquele contexto, podemos encontrar uma miríade de acontecimentos que associaram grupos que habitavam zonas rurais com partidos, movimentos, organizações e governo em várias partes do país ${ }^{3}$. Ligas Camponesas, sindicatos de trabalhadores rurais e o Movimento dos Agricultores Sem Terra (Master) foram sem dúvida as principais manifestações públicas daquela onda. Sobre o sindicalismo rural há um extenso e contínuo investimento de pesquisa que nos permite compreender a forma pela qual o direito do trabalho se expandiu para além das fábricas e espaços urbanos (Palmeira, 1978; Sigaud, 1979; Camargo, 1973; Rosa, 2004). Sobre as ligas, surgidas em Pernambuco, apesar de alguns trabalhos importantes como os de Azevedo (1982) e Bastos (1984), ainda são raros os investimentos que tentam aportar novas perspectivas teóricas e mesmo documentais ao que já conhecemos. Já sobre o Master, até os dias de hoje há apenas um trabalho (Eckert, 1984), não publicado, que serve de apoio a todos os que queiram conhecer mais a formação e

\footnotetext{
${ }^{3}$ Para uma descrição acurada daquele momento histórico, ver o trabalho de Camargo (1973).
} 
o desenvolvimento do primeiro movimento que se autodenominou "sem-terra".

A falta de maior investimento sobre a história desse movimento conduz geralmente a uma dicotomia interpretativa que o classifica como um braço do governo Brizola (Carini e Tedesco, 2007) ou como um grupo autônomo que teria imposto o tema da terra àquele governo. Essa dualidade, ancorada mais em um modelo interpretativo (autonomia ou cooptação) do que em qualquer evidência de pesquisa, tornou-se uma barreira para se refletir sobre como os "sem-terra" de outrora se ligariam aos sem-terra de hoje, emblemados pelas bandeiras do MST.

Nas próximas páginas procuraremos, a partir de um investimento recente em novas e velhas fontes sobre alguns acontecimentos que envolveram o Master, mas que não se limitam a ele, construir um quadro interpretativo que permita pensar a questão dos sem-terra na longa duração dos 200 movimentos sociais brasileiros.

\section{Os sem-terra no governo Brizola}

O Master foi fundado em meados de 1960 pelo prefeito da cidade de Encruzilhada do Sul - localizada na região central do Rio Grande so Sul - no momento em que um fazendeiro de um grupo político opositor tentava expulsar da terra agricultores, alegando ser ele o verdadeiro dono da terra. Milton Serres Rodrigues era membro do PTB, o mesmo partido de Brizola, e contou com o apoio do governador para organizar núcleos do Master ali e em outros municípios. Não temos notícia de nenhum tipo de ação coletiva que tenha sido realizada para garantir a posse daquelas terras, sabemos apenas que houve a formação do movimento. Passado o evento de Encruzilhada do Sul, que resultou na desapropriação da terra pelo governo do Estado, não há notícia de nenhuma outra mobilização ou ação pública desse movimento até 1962, quando começaram as invasões, 
como veremos mais adiante ${ }^{4}$. Tivemos até ali um movimento sem ações coletivas, por assim dizer.

Isso não significa, no entanto, que os sem-terra tenham saído da pauta do governo. Uma série de documentos do governo do Estado e cartas pessoais, recolhidas no arquivo de um antigo funcionário do IGRA - Instituto Gaúcho de Reforma Agrária, mostram que entre 1960 e 1961 temas relacionados à condição de vida dos habitantes das zonas rurais tornam-se constantes em atos do governo.

Em primeiro lugar, foi instituída a Comissão Estadual de Terra e Habitação que deveria promover a "a aquisição de terras para agricultores e suas organizações" ${ }^{2}$, antes mesmo da formação do Master. Alguns meses depois, um relatório de atividades da mesma secretaria previa a "desapropriação $e$ recebimento de glebas" por parte do governo estadual ${ }^{6}$. A Ceth realizou ainda, durante o ano de 1960, um levantamento pormenorizado do número de propriedades com mais de dois mil hectares em todo o Estado e concluiu que o "latifúndio" era um dos principais problemas enfrentados pelos gaúchos.

Em meados de 1961 foi criado um grupo de trabalho, liderado pelo mesmo funcionário que realizava os levantamentos das propriedades pela Ceth e que prepararia a formação do Instituto Gaúcho de Reforma Agrária. É nos documentos do IGRA que a expressão "sem-terra" vai aparecer pela primeira vez. Segundo o que se pode ler nas publicações do Instituto, a política de colonização e redistribuição de terras teria como alvo atender especificamente os "sem-terra". É importante notar que, nesse decreto, a categoria representa todos os grupos que viviam em condições consideradas precárias pelo governo. Os sem-terra são, naquele momento, alvos preferenciais de políticas públicas voltadas para as áreas rurais.

\footnotetext{
${ }^{4}$ Nesse tempo, o Master ganhou um estatuto e uma carta de fundação que foi lida por um deputado do PTB em uma sessão no Congresso Nacional,

${ }^{5}$ Decreto 11.201, de 29 de fevereiro de 1960.

${ }^{6}$ Relatório de atividades da Ceth de 1960
} 
A institucionalização dos sem-terra como um problema público esteve acompanhada pela formação de um amplo aparato burocrático que evoluiu, como vimos, de uma comissão genérica, passando por um grupo de trabalho até a formação de um órgão exclusivo para cuidar do tema. Apesar desse impressionante grau de planejamento não há informações, durante os anos de 1960 e 1961, sobre ações efetivas relativas à colonização ou desapropriações de terras, como previam as medidas públicas ao longo do período $^{7}$. Mesmo demonstrando empenho em fazer dos semterra uma categoria de ação estatal, o governo Brizola não teria tomado nenhuma outra medida que se assemelhasse ao que ocorrera em Encruzilhada do Sul no ano anterior. Esse quadro viria a mudar completamente em janeiro de 1962, com a primeira ocupação coletiva de uma fazenda privada de que se tem notícia naquele Estado.

\section{Quando os sem-terra começam a invadir}

No dia 11 de janeiro de 1962 algumas centenas de pessoas montaram um acampamento com barracos de madeira e barracas de lona de caminhão às margens da rodovia que liga os municípios de Passo Fundo e Ronda Alta. Ali ficava a Fazenda Sarandi, propriedade de um grupo uruguaio que utilizava apenas uma pequena parte dela para exploração de madeira.

Eckert (1984) e Tedesco e Carini (2007) são unânimes em atribuir a ação ao Master. Porém, ao voltarmos aos documentos e fontes por nós levantados e após consultar o material citado por esses autores, não encontramos nenhuma menção à participação do Master, seja na organização, seja na execução da montagem dos acampamentos. Investimos, a partir daí, na investigação sobre o modo pelo qual se havia

\footnotetext{
${ }^{7}$ Salvo os casos da aquisição de propriedades nas cidades de São Jerônimo (1158,31 ha.) e Canguçu (595,9484 ha.), dos quais não se conhece o destino da terra, e da área de Encruzilhada do Sul. Todos em 1960.
} 
organizado aquela ação, que levou o governo Brizola a desapropriar a área dois dias após o evento.

O grupo que chegou à Fazenda Sarandi era formado em sua quase totalidade por pessoas que vinham do município de Nonoai, distante $100 \mathrm{~km}$ dali. Segundo entrevistados que participaram da mobilização das pessoas e da montagem e organização do acampamento, tudo havia sido preparado pelo prefeito da cidade, Jair de Moura Calixto, filiado ao PTB. Além de correligionário de Brizola, Calixto era também seu primo.

A proximidade entre Calixto e Brizola lembrava também as relações que envolviam o fundador do Master, Milton Serres Rodrigues, e o governador. No entanto, a pesquisa mais aprofundada sobre o caso de Nonoai começou a revelar nos fios que complicam a interpretação mais espontânea de que se trataria de uma ação ordenada pelo governador $^{8}$. Apesar de primos e membros do mesmo partido, a relação entre Calixto e Brizola tinha altos e baixos. Em parte porque o prefeito de Nonoai era conhecido por atos intempestivos, como, por exemplo, quando ao perder a prévia do PTB para escolha do candidato à prefeitura, se lançou por outro partido para, depois de ter vencido o pleito, voltar ao PTB. Ou ainda quando interrompeu, armado, uma reunião de opositores em um clube da cidade.

Quatro meses antes da invasão, Calixto havia sido uma das figuras importantes da Campanha da Legalidade que, liderada por Brizola, garantiu a posse do vice-presidente João Goulart após a renúncia de Jânio Quadros. Naquele evento, Calixto montara uma guarda armada de mais de mil homens na cidade de Nonoai para proteger o Rio Grande do Sul de uma possível invasão vinda de Santa Catarina. O sucesso da resistência catapultou a populari-

\footnotetext{
${ }^{8}$ Infelizmente, não há trabalho conhecido que tenha se dedicado a um estudo mais aprofundado do que se passou na cidade de Encruzilhada no momento de fundação do Master.
} 
dade do prefeito na cidade e vários dos homens, que compunham a guarda da legalidade, foram depois usados na mobilização de moradores da região para participar da invasão da Fazenda Sarandi. Nos dias prévios à invasão viase, segundo relatos, uma faixa estendida na praça principal da cidade: "Os com terra com Cristo, os sem-terra com Jair Calixto".

Mas de onde surgira a ideia de promover a invasão da Sarandi e de retomar o uso da expressão sem-terra? Após mais de dois anos analisando documentos e realizando entrevistas, não foi possível determinar com precisão as razões de Calixto. Por isso, preferimos inscrever essa atitude em uma figuração que nos permita compreender, ao menos, o contexto do qual ele se aproxima na questão dos sem-terra. Nos meses que se seguiram à Campanha da Legalidade, o governo do Estado teria financiado a participação de um grupo de dirigentes do Master, que naquele momento já 204 contava com membros do Partido Comunista Brasileiro em sua direção no I Congresso Nacional de Lavradores e Trabalhadores Rurais. Naquele evento, ocorrido em Belo Horizonte, os membros do Master, e os das ligas camponesas, em conjunto, propuseram e aprovaram a tese "reforma agrária na lei ou na marra", abrindo as portas para uma intensificação das lutas rurais em todo o país. No Rio Grande do Sul, há relatos de uma série de encontros entre os líderes do Master, todos eles ligados a partidos políticos, e o governador, no mês de dezembro de 1961. Nesses encontros teria sido discutida, segundo Eckert (1984), a possibilidade de se montar acampamentos de sem-terra em algumas das principais cidades do Estado. No mesmo período, há relatos de que Brizola chamara Calixto em seu gabinete para tratar também dessas questões. Pouco se sabe do que foi tratado nesse encontro. Entre as versões que foram citadas nas entrevistas, havia uma que dizia ter havido uma tratativa entre Brizola, o prefeito da cidade de Sarandi e Jair Calixto 
para a invasão da Sarandi. No entanto, o prefeito de Sarandi e o secretário de governo teriam convencido Brizola a não realizá-la, pois assim colocaria um setor importante da base de apoio do PTB - os grandes fazendeiros - contra o governador.

Em Nonoai, Calixto, com ajuda de militantes dos dissidentes do PCB e não com lideranças do Master, avisou as pessoas que haveria uma terra que poderia ser ocupada por eles na cidade de Sarandi. Um de seus milicianos da legalidade foi encarregado de encontrar o lugar propício para a montagem do acampamento. Os fatos que se seguem são mais conhecidos e relatam o jipe de Calixto liderando uma caravana de caminhões com as carrocerias abarrotadas de homens pelas estradas de chão da região, um pernoite na localidade Ronda Alta, e a chegada na manhã do dia seguinte ao local da invasão.

Em nenhum dos documentos relativos ao evento ou nas entrevistas que fizemos houve menção ao Movimento dos Agricultores Sem-Terra ou aos seus diretores. As figuras centrais são Calixto e Brizola, que visitou pessoalmente a área dias depois. Uma das possíveis versões sobre o fato pode nos remeter justamente ao caráter intempestivo de Calix to que, mesmo contra a vontade do governo, teria levado a cabo a mobilização das pessoas. Depois de montado o acampamento não haveria alternativa para Brizola que não fosse apoiar a ação que, para muitos, fora feita em seu nome.

Se até aquele momento o Master não aparecia como protagonista, nas semanas seguintes o movimento e seus líderes começariam a ter um papel mais relevante. Em algumas das fotos da visita do governador ao acampamento da Sarandi aparece a figura de Milton Serres Rodrigues e, posteriormente, os jornais da região divulgariam que o movimento estaria cadastrando as famílias sem-terra no acampamento. Na Sarandi, portanto, não há nada oficial que nos aponte o Master como capitaneando os sem-terra. 
Em poucos dias, o movimento chegaria a todos os jornais, quando um novo acampamento foi montado na localidade do Banhado do Colégio, na cidade de Camaquã. Desta feita, o organizador era conhecido de todos e identificava-se como o presidente da associação local dos sem-terra. Assim como na Sarandi, o governo também desapropriou a área. Nos meses seguintes, foram contabilizadas dezenas de acampamentos em todo o Estado. Todos organizados por associações de sem-terra.

No mês de abril de 1962, o IGRA foi finalmente posto em marcha. Projetos de colonização foram feitos para o Banhado do Colégio e para a Sarandi. Uma parte da reserva florestal de Nonoai também foi transformada em projeto de colonização para abrigar famílias que haviam se cadastrado em um acampamento que fora formado ali pelo Master com a ajuda de Calixto. No mês de março de 1962, o próprio Brizola doou mil hectares de uma das fazendas de sua mulher para um pla206 no de colonização, cujos beneficiários, moradores do local, foram escolhidos por ele próprio. Nesse mesmo mês, o governo estadual publicou nos jornais do Estado um apelo para que grandes proprietários seguissem seu exemplo e doassem parte de suas terras para abrigar famílias de sem-terra.

O quadro acima aponta para o processo de construção política de uma categoria que apareceu primeiro nos documentos do governo do Estado, foi mobilizada na tentativa de expulsão da família de Encruzilhada do Sul e terminou por se tornar emblema de um movimento que tinha como seus líderes membros de partidos políticos ligados ao governo. Apesar de o Master existir formalmente, não há registro de suas ações até que o acampamento da fazenda Sarandi tenha acontecido.

Após o primeiro acampamento, cuja paternidade não é possível determinar, observamos que o Master se organiza para fazer fluir a política pública que fora gestada no governo Brizola, mas que não fora posta em prática ao longo do 
ano de 1961. Se a categoria de sem-terra foi criada durante aquele governo, ela logo sairia de seu controle. Com o acampamento da Sarandi e com a presença do Master nos demais casos, os sem-terra se tornaram uma força relativamente autônoma. O próprio governador viria a público, em 1962, pedir uma trégua nos acampamentos por meio da formação de uma comissão que incluía líderes do Master, membros do governo e latifundiários.

Há sobre esse caso uma mistificação constante de que tudo fora minuciosamente planejado pelo governador, o que corroboraria estereótipos como de "caudilho" e "populista" que tanto agradam certos cientistas sociais. Nossa hipótese, seguindo os caminhos que já havíamos trilhado em Sigaud, Rosa e Macedo (2008), é que houve naquele período um enredamento entre mobilizações de um movimento social, a sensibilidade de certos funcionários do governo para o tema das precárias condições de vida nas áreas rurais, condições estruturais nas alianças internas ao governo Brizola e, principalmente, ações não previstas, como a de Jair Calixto. Tal enredamento tomou um sentido muito específico: deu vida social a uma categoria amorfa que estava nos planos do governo e que não foi apenas uma invenção de um líder político.

\section{A volta dos sem-terra: dezesseis anos depois}

O governo Brizola terminou no início de 1963 sem que a maioria dos acampamentos tivesse o mesmo destino da Fazenda Sarandi ou do Banhado do Colégio. Mesmo entre as famílias que haviam sido cadastradas pelo Instituto Gaúcho de Reforma Agrária nos acampamentos que se tornaram projetos de colonização, nem todas puderam ser contempladas. Com a mudança de governo, os acampamentos liderados pelo Master foram reprimidos e, após o golpe militar de 1964, seus principais organizadores foram presos ou fugiram do país. 
Apesar disso, permaneceram naquela região centenas de pessoas cadastradas como agricultor sem-terra. Essas pessoas que não receberam terra na época acabaram por voltar para seus lugares de origem, principalmente para Nonoai e estabeleceram-se na terra que pertencia à reserva indígena dos Kainganges.

Na década de sessenta era possível permanecer nas terras indígenas da região sob a condição de pagamento de uma taxa de arrendamento, mas a partir da promulgação do chamado Estatuto do Índio em 1973, a prática foi proibida. No caso específico da reserva de Nonoai, havia mais de mil famílias vivendo sob essas condições, muitas das quais com passagem pelo acampamento da Fazenda Sarandi em 1962.

Uma questão central nesse contexto é que os agricultores, desta feita autodenominados colonos, passaram a ser ameaçados de expulsão com base em um decreto do governo que visava assegurar ao indígena o direito à terra ${ }^{9}$. Após 208 três anos de negociações frustradas entre o Instituto Nacional de Colonização e Reforma Agrária, a Fundação Nacional do Índio, colonos e indígenas, os agricultores acabaram por ser expulsos de suas casas em maio de 1978. A maioria das famílias saiu da reserva indígena apenas com suas roupas, poucos móveis e sem colher as lavouras que haviam plantado e nas quais estava investida a maior parte de seu capital. Algumas conseguiram se alojar em casas e propriedades de amigos e parentes na própria região. Para aqueles que não tiveram essa sorte, o destino foi um acampamento improvisado na localidade de Taquaruçuzinho.

Diferentemente do que ocorreu na década de 1960, o decreto do governo não criou uma categoria formal; dessa vez, criou um novo e palpável contingente de sem-terra. Mais de mil famílias que, de uma hora para outra, perderam sua principal forma de subsistência. A ideia de que a responsabi-

\footnotetext{
${ }^{9}$ A palavra colono é utilizada no Rio Grande do Sul e Santa Catarina.
} 
lidade sobre o que ocorrera na reserva indígena fora obra do governo estadual ficou clara a partir do momento em que as famílias expulsas começaram a procurar novas terras. Completamente descapitalizados, os agricultores foram em busca de terras públicas que não fossem devidamente utilizadas.

A primeira tentativa ocorreu ainda em maio de 1978, com a entrada de algumas famílias em uma área de reserva florestal pertencente ao governo, na cidade vizinha de Planalto. Naquela ocasião, moradores vizinhos à reserva florestal avisaram seus parentes expulsos da terra indígena de que havia uma terra do Estado sem uso. As conexões com 1962 mostram-se mais fortes ainda porque esses parentes estabelecidos em Planalto viviam em uma área - a chamada Quarta Seção - que fora desmembrada pelo governo Brizola da reserva florestal no ano de 1963 para assentar famílias de sem-terra que haviam sido cadastradas no acampamento liderado por Jair Calixto. Ou seja, as famílias que foram beneficiadas na década de 1960 esperavam que, numa situação que já se configurava como de calamidade pública, o governo do Estado reproduzisse a mesma fórmula do passado. O resultado prático não foi o esperado. As famílias vindas de reservas indígenas foram expulsas da área pela polícia de Nonoai no mesmo dia em que entraram. Para as pessoas que estiveram na invasão e que conseguimos entrevistar, a ação não teria sido bem-sucedida devido à intervenção de políticos locais que não deixaram o caso chegar ao governador do Estado. Em sua perspectiva, o problema foi justamente a não interferência do governo na questão, que foi vista apenas como um conflito dos manifestantes com a polícia.

A ideia de que o alvo estava correto e de que o problema fora de ordem local, ajuda-nos a compreender porquê, poucos dias depois, pessoas pertencentes ao mesmo grupo, com outras dezenas de famílias, invadiram outra área de reserva florestal, na cidade de Rondinha. Localizada a mais de 100 km de Nonoai, a reserva de Rondinha guardava mais 
uma conexão com os fatos ocorridos em 1962. Ela fora parte desmembrada da Fazenda Sarandi quando ocorreu a desapropriação da área por Leonel Brizola. Àquela altura veio à tona o fato de que nem toda a área que fora desapropriada na década anterior havia sido distribuída para os sem-terra. Havia, além da reserva florestal, duas glebas (Brilhante e Macali) somando quase quatro mil hectares que, depois de desapropriada a Sarandi, foram arrendadas pelo governo estadual a grandes fazendeiros. Como os agricultores saídos da área indígena teriam elegido aquela área? Nossa pesquisa não encontrou respostas mais conclusivas para o fato a não ser de que se tratava de uma terra do governo, uma terra cujo uso seria passível de negociação.

Ao contrário do que ocorrera em Nonoai, a invasão da reserva de Rondinha foi levada ao conhecimento do governo estadual. Segundo algumas pessoas que lá estiveram, o acampamento montado no local fora visitado pelo então

210 pretendente ao cargo de governador do Estado (naquele período não havia eleição direta, e o governador era indicado pelo presidente da República). Na ocasião cadastraramse famílias sem-terra que permaneceram no acampamento por mais de um mês. Feito o cadastramento, os agricultores voltaram para as casas de parentes e amigos que os acolheram após a expulsão.

Enquanto o acampamento esteve montado, a área foi cercada pela polícia militar, que impediu a entrada de novas pessoas. No entanto, em poucos dias formou-se mais um acampamento no interior da reserva florestal de Rondinha. Dessa vez, os invasores não eram pessoas que foram expulsas de suas terras, mas jovens agricultores, filhos dos beneficiários da antiga Fazenda Sarandi que viviam nas terras de seus pais. Os jovens moradores da área, ao verem o acampamento montado pelas pessoas vindas de Nonoai, decidiram mobilizar-se para que, caso a terra remanescente da Fazenda Sarandi viesse a ser distribuída, a prioridade fosse 
dada aos filhos dos antigos assentados. Segundo um desses jovens da época, havia um sentimento de que o Estado seria também responsável pelo destino dos filhos dos primeiros beneficiários da área. Essa ideia teria surgido em razão de promessas feitas pelos funcionários do Estado que administraram o projeto de colonização idealizado por Brizola, e executado em outras bases no governo de Ildo Meneghetti, em 1963 e 1964.

A invasão, promovida pelos grupos que foram desalojados em Nonoai e que buscavam terras que fossem do governo que os expulsou para que continuassem a viver como agricultores, trouxe à tona um compromisso que havia sido firmado por um outro governo 16 anos antes. Articulando compromissos passados e presentes dos governos com diferentes gerações de sem-terra que haviam emergido como problema para o Estado em situações completamente distintas, ambos visavam envolver o poder público na resolução do problema dos sem-terra.

A ideia de que a questão dos sem-terra de Nonoai era um problema que deveria ser solucionado por meio da transferência de terras do Estado foi reforçada nos dias seguintes, quando um novo grupo, também formado por expulsos da área indígena, chegou ao local. Como a polícia não permitiu sua entrada no acampamento da reserva florestal de Rondinha, o grupo decidiu invadir e montar um novo acampamento na área da antiga Fazenda Sarandi que fora arrendada para grandes fazendeiros. O grupo permaneceu na Gleba Brilhante por mais de um mês e chegou a plantar uma roça de milho. No entanto, como a área estava sendo utilizada por entes privados, esse grupo não ganhou a mesma atenção daqueles que invadiram a reserva florestal de Rondinha. Eles não foram cadastrados. Foram apenas cercados pela polícia e acabaram tendo de voltar para as casas de amigos e parentes ou para o acampamento que os abrigaram após a saída da área indígena. 
Esses dois casos reforçam nosso argumento na relação obrigatória entre os sem-terra e o Estado na gênese das ações coletivas por terra no Brasil. Para os acontecimentos de 1978, o fato de que, ao saírem da reserva indígena, as famílias em grupos heterogêneos tenham participado de três invasões e de que todas elas tenham tido lugar em terras públicas é inegável. Durante a pesquisa, não encontramos nenhuma referência quanto à possibilidade de entrada em terras privadas nas entrevistas das pessoas envolvidas nos acampamento nem em documentos.

Como é possível perceber, apesar da intenção de mobilizar o governo estadual para resolver seu problema, os "colonos sem-terra", como ficaram conhecidos, não conseguiram obter uma resposta imediata, como ocorrera em 1962. Depois de mais de um mês de calamidade, a proposta apresentada pelo Estado foi o confinamento das famílias em um parque de exposições na cidade de Esteio (a cerca de $20 \mathrm{~km}$ de Por212 to Alegre) até que uma solução definitiva fosse encontrada. Para cerca de 700 famílias, essa foi a saída. No parque ocuparam os espaços da exposição e receberam comida do governo estadual. Porém, sua liberdade de ir e vir era restrita, pois somente podiam deixar o local com autorização do chefe de polícia que ficou encarregado do controle do acampamento. Naquele tempo, algumas das pessoas foram autorizadas a trabalhar em serviços domésticos na casa de políticos que se ofereciam para ajudar as famílias.

O deslocamento dos sem-terra para mais de $400 \mathrm{~km}$ de sua região de origem envolveu definitivamente o governo estadual com a questão. Seria preciso recorrer a uma solução definitiva para o caso. Durante os meses seguintes, a primeira alternativa proposta foi o envio das famílias para os projetos de colonização da região norte, especialmente do Mato Grosso $^{10}$. Algumas famílias aceitaram a oferta e foram levadas de

\footnotetext{
${ }^{10}$ Para maiores informações sobre os projetos de colonização que envolveram os
} 
avião para as bordas da Floresta Amazônica; outras, a minoria, se negaram a deixar o Rio Grande do Sul. Para as famílias que permaneceram, foi oferecido o assentamento em uma propriedade do governo do Estado na cidade de Bagé, na fronteira com o Uruguai (distante mais de $600 \mathrm{~km}$ de Nonoai). O projeto de colonização Nova Esperança foi efetivado no início do ano de 1979 e para lá foram transferidas 125 famílias que receberam lotes de terra ${ }^{11}$.

A mobilização do governo resolveu parcialmente o caso. Temos de lembrar que perto de 700 famílias passaram pelo parque de Esteio, mas que mais de 1.000 haviam sido expulsas da reserva. A atenção dada aos colonos que estavam mais necessitados, por meio da obtenção de terras, foi fundamental para despertar o desejo das demais famílias que haviam encontrado abrigo em terras alheias. Muitas das pessoas que foram contempladas com terras em Mato Grosso ou em Bagé eram parentes dos que haviam ficado em Nonoai e assim fizeram circular a informação de que o Estado lhes estava conseguindo terras.

As famílias que restaram em Nonoai formaram, no ano de 1979, uma comissão que teve a ajuda de sindicalistas, agentes da Comissão Pastoral da Terra e de um funcionário da Secretaria Estadual de Agricultura na intermediação das negociações com o governo estadual. Entre janeiro e setembro daquele ano várias reuniões foram feitas, e as únicas propostas concretas se referiam à ida das famílias também para Mato Grosso. De certa forma, a atuação dessa comissão serviu para estender o compromisso do governo para todos os expulsos da área indígena. Sem resultados efetivos, os agricultores e seus parceiros decidiram realizar uma nova invasão de terras. Em setembro de 1979, um grupo

sem-terra de Nonoai, consultar o trabalho de Tavares dos Santos (1993).

${ }^{11}$ Nem todas as famílias foram incluídas nessas duas alternativas. Para algumas delas foram oferecidas aposentadorias ou empregos definitivos em propriedades rurais, intermediados por funcionários do governo. 
de pouco mais de cem famílias montou um acampamento na Gleba Macali - o único pedaço da Fazenda Sarandi que não havia ainda sido invadido. Mais uma vez a opção foi por uma terra que pertencia ao governo estadual e que estava arrendada a uma empresa madeireira.

O acampamento da Macali logo recebeu atenção do governo estadual que, em menos de um mês, autorizou os agricultores a iniciar o cultivo de uma lavoura na área e montou um escritório no local para conduzir o processo de assentamento de 104 famílias. Assim que o governo sinalizou positivamente para o acampamento da Macali, foi montado um outro acampamento na Gleba Brilhante - a mesma que havia sido invadida em 1978 e que faz fronteira com a Macali - com as família restantes que haviam sido expulsas da reserva. Ao verem que os acampamentos da Macali e da Brilhante resultariam, cedo ou tarde, na distribuição das terras às famílias vindas de Nonoai, os filhos dos assentados 214 no governo Brizola - os chamados filhos da Sarandi - montaram novamente um acampamento próprio, desta feita na Brilhante.

Em 1980, o governo estadual finalmente concedeu os títulos de posse das terras da Macali e da Brilhante aos colonos vindos de Nonoai, tornando as glebas assentamentos oficiais do Estado. Ao oficializar a posse das áreas, foi criado um novo problema: não havia terras suficientes para abrigar todos os acampados. Certos de que a questão dos sem-terra já havia sido incorporada à agenda do governo, os agentes da CPT e outras lideranças das invasões decidiram ocupar uma outra fazenda contígua, que estava em processo de desapropriação pelo governo estadual havia quase uma década. A fazenda Anoni fora desapropriada para receber as famílias removidas para a construção da barragem do Passo Real. No entanto, apesar de algumas delas terem sido efetivamente assentadas ali em 1973, a área continuava em disputa judicial. 
O acampamento da Anoni foi violentamente reprimido pela polícia e as famílias foram levadas para as margens da estrada que liga Ronda Alta a Passo Fundo, ocupando parte do lote de um assentado da Macali. Ou seja, os acampamentos ocorridos na área da Fazenda Sarandi entre 1962 e 1980, ao mesmo tempo que criaram um contingente de "sem-terra" como categoria de ação política, contribuíram para a formação de um estoque de terras. Terras que permitiram o assentamento de duas gerações de famílias e ainda serviriam de base de apoio para novos acampamentos.

O acampamento montado em finais de 1980 ficou conhecido pelo nome de Encruzilhada Natalino e recebeu não apenas aqueles que haviam sido expulsos da reserva de Nonoai. Em pouco tempo, o local se tornou abrigo para milhares de famílias de agricultores que viviam na região em terras de familiares ou arrendadas e que buscavam conseguir um pedaço próprio para cultivar e morar.

Além dessas famílias da região, o acampamento passou a atrair outras que, quando expulsas da reserva indígena, foram levadas para Mato Grosso, onde não se adaptaram às condições de vida na nova região. Esses "retornados", ao saberem que seus antigos vizinhos haviam sido assentados na própria região, decidiram voltar para ficar mais próximos de suas famílias ${ }^{12}$.

Uma amostra da mudança na composição do acampamento entre a Natalino, a Macali e a Brilhante são os depoimentos colhidos e citados no livro de Méliga e Janson (1982). Entre os entrevistados, havia no acampamento 13 famílias de Ronda Alta, três retornados do Mato Grosso e cinco famílias que, após serem expulsas da reserva, ficaram pelos arredores de Nonoai e que não se haviam

\footnotetext{
12 Tavares dos Santos (1993) apresenta uma descrição bastante precisa das condições precárias da maioria dos projetos de colonização da Amazônia. O trabalho dedica-se ainda a acompanhar e entrevistar alguns desses retornados em sua volta ao Rio Grande do Sul nos anos oitenta.
} 
engajado nos acampamentos anteriores. Há registros também da presença no acampamento de muitos dos filhos de famílias que haviam recebido terras na Fazenda Sarandi na década de 1960 .

Tendo em vista esses dados, podemos compreender que a Encruzilhada Natalino promoveu a questão dos semterra para além do grupo que fora, por inabilidade do Estado, desalojado repentinamente. Naquele local, os sem-terra voltaram a ter o mesmo sentido que lhes fora atribuído no governo Leonel Brizola e deixaram de ser considerados um grupo específico: os sem-terra passaram a ser vistos como as famílias que viviam em áreas rurais sob condições precárias de subsistência, especialmente os não proprietários.

Não podemos, no entanto, pensar que os sem-terra fossem na Encruzilhada Natalino apenas uma categoria com efeito estatal, como acontecera nos primórdios do Master. O relativo sucesso reivindicatório dos acampamentos ante216 riores contribuiu para que pessoas que levavam suas vidas sob condições de "arrendatário", "meeiro" ou mesmo como "filhos" de pequenos proprietários passassem a sentir-se também como sem-terra. Nossa hipótese é de que, nesses casos, sentir-se "sem-terra" era sentir-se apto a reclamar benefícios estatais, principalmente a redistribuição de terras para a agricultura.

O acampamento da Encruzilhada Natalino tornouse também um símbolo da luta contra a ditadura militar, atraindo a atenção de militantes de todo o país para o problema dos sem-terra. Ao elevá-los a uma categoria símbolo da resistência à ditadura, os acontecimentos da Encruzilhada lançaram bases sólidas para a constituição de um movimento social que, devemos ressaltar, não existiu como organização até 1984 .

Antes do surgimento do MST, os governos estadual e federal tiveram, pela primeira vez desde 1962, de desapropriar terras privadas para assentar acampados na Encruzi- 
lhada Natalino, pois já não havia mais terras estatais para abrigá-los. Entre 1981 e 1984, foram compradas terras pelo governo do Estado nas cidades de Palmeira das Missões e Salto do Jacuí, nos arredores de Ronda Alta ${ }^{13}$.

Assim, nos anos 1980 e 1990, já sob a organização do MST, as ocupações - e não mais invasões - ficariam marcadas por uma luta do movimento para que o Estado passasse a usar seus recursos na compra de terras privadas. Além da compra de terras, as ações do MST, principalmente na forma de ocupação de prédios públicos, passam a pedir aos governos créditos para a construção de moradias, financiamento de lavouras dos assentados e assistência técnica. Houve casos de ocupações que chegaram a pedir a realização de concurso público para o Instituto Nacional de Colonização e Reforma Agrária ${ }^{14}$, pois a demanda do movimento superava em muito a capacidade de trabalho dos quadros daquela autarquia.

\section{MST na década de 2000: cruzando o país}

Em outros trabalhos (Rosa, 2004 e 2006) procurei demonstrar como o MST se estabeleceu no estado de Pernambuco na década de 1990, tornando aquela região o maior foco de ocupações de terra de todo o país. Para além dos processos locais, que envolveram uma acirrada disputa com os sindicatos de trabalhadores rurais por representação e por áreas a serem ocupadas, o caso pernambucano revelou também uma proliferação de outros movimentos de sem-terra. Por volta de 2003, haviam sido contabilizados pelo Incra regional 14 movimentos diferentes que organizavam ocupações e reivindicavam desapropriações de terra.

\footnotetext{
${ }^{13}$ Sobre a relação de terras desapropriadas pelo governo na época, ver o trabalho de Navarro et al. (1999).

${ }^{14}$ Disponível em: http://noticias.terra.com.br/brasil/interna/0,,OI682608EI1774,00-MST+inicia+Jornada+Nacional+de+Luta+com+ocupacoes.html. Acesso em: 18 nov. 2008.
} 
O estudo de caso de alguns desses movimentos, como o Movimento dos Trabalhadores Brasileiros Sem-Terra (MTBST) e o Movimento dos Trabalhadores Rurais e Urbanos do Brasil (MTRUB), entre outros, contribuiu para que fossem trazidos ao debate novos elementos sobre o sentido das mobilizações do MST. Especialmente no caso desses dois movimentos, seus líderes tomaram parte em acampamentos e ocupações promovidos pelo MST nos anos noventa e tornaram-se também militantes daquela organização. Ambos experimentaram uma ruptura com o MST no início da década de 2000 que resultou na formação de movimentos independentes.

Quando olhamos os casos com mais cuidado, foi possível perceber que, nas duas situações, o rompimento com o MST ocorreu a partir do momento em que este movimento deixou, por razões diversas, de priorizar os casos de acampamentos em que estavam essas lideranças. Analisando deti218 damente o significado dessa priorização, percebemos que se tratava de casos cujo processo de desapropriação da terra desejada estava parado e havia sido colocado como secundário em relação a outros, ou casos de falta de distribuição de cestas básicas por parte do governo federal. Em última instância, tratava-se de situações que, nas palavras de seus protagonistas, indicavam que o movimento já não estava atendendo às expectativas daqueles que se autoidentificavam como sem-terra: estabelecer uma relação proveitosa com o Estado e seus governos.

A formação de novos movimentos, como indicamos em Rosa (2007), reiterou a fórmula que deu origem e que consagrou o MST como a mais importante organização política do Brasil nos últimos 15 anos. Esses novos e pequenos movimentos se legitimaram diante dos sem-terra porque passaram a ter contato direto com o Incra e seus funcionários em Pernambuco. Situação que o MST, com suas centenas de acampamentos, nem sempre é capaz de garantir unifor- 
memente. Sem a presença estatal, na forma de processos de desapropriação, assistência técnica ou de cestas básicas, a situação desses movimentos se torna precária, pois as famílias deixam os acampamentos em busca de alternativas melhores, não necessariamente como sem-terra. Esses abandonos, que ocorreram nos casos do MTRUB e do MTBST também pouco tematizados pela literatura, mostram como a situação social de sem-terra não é uma situação monolítica, mas é uma entre outras tantas. A "situação de sem-terra" tem sido, quando pensamos a partir do caso pernambucano, uma forma legítima de reivindicar recursos estatais.

Não podemos esquecer, no entanto, que há outras formas de se relacionar com o Estado e que a vida das pessoas que em determinado momento se aglutina sob a organização de um desses movimentos, mesmo quando elas estão sob as lonas dos acampamentos, não se resume a isso. Elas mantêm suas famílias, suas relações políticas prévias e outros laços que, com maior ou menor intensidade, podem levá-las por outros caminhos que não seja a "luta pela terra". Essa questão torna-se compreensível justamente se levarmos em conta que sua vida de sem-terra se iniciou apenas quando elas passaram voluntariamente a tomar parte nos acampamentos do MST e dessas novas organizações. Esse engajamento, no entanto, não pode ser visto como uma reconversão de toda a história prévia dos sujeitos que nela entram, nem mesmo como primeira e única experiência política. Ela é uma, entre muitas outras, formas de se apresentar ao governo.

\section{Estado e ações coletivas em perspectiva interdependente}

Ao percorrermos um caminho de mais de quarenta anos em que a categoria sem-terra tem sido utilizada para mobilizar e aglutinar pessoas que reivindicam terras ao Estado e seus governos, trouxemos à tona aquilo que defendemos ser o ponto forte da permanência do MST como movimento social no Brasil: sua relação com o Estado. 
A partir do Master, dos acampamentos realizados no interior do Rio Grande do Sul na década de 1960 e de sua imbricação com processos de transformação nas prioridades do governo de Leonel Brizola, fomos conhecendo a figuração da qual a categoria política dos "sem-terra" emerge. Ela surgiu de um jogo de forças não necessariamente planejado, que tinha como sujeitos centrais pessoas que ocupavam cargos públicos. Foram prefeitos, secretários de Estado e até mesmo um governador que protagonizaram a consagração não planejada dessa categoria ao torná-la objeto de políticas públicas que permitiriam ao Estado dirimir problemas sociais em áreas rurais. A mobilização desses trabalhadores rurais na Fazenda Sarandi em janeiro de 1962, como forma de reivindicação, imprimiu-lhe a marca de ação coletiva. Uma ação que, defendemos, não fora organizada pelo Master. Este movimento teria se apropriado da forma acampamento (Sigaud, 2000) no momento em que a ação de desa220 propriação da Fazenda Sarandi, realizada pelo prefeito de Nonoai e seus correligionários, transcorreu de forma legítima. Assim, tanto o governo, como o Master e as pessoas que desejavam seu próprio pedaço de terra, passaram a confiar mais nessas ações coletivas. E essa confiança advinha, segundo os vários depoimentos que colhemos na antiga Fazenda Sarandi, de como o vizinho, o amigo ou o parente também conseguiram terras por esses meios oficiais. Todas essas ações foram garantidas, desde o começo, por sujeitos que ocupavam legitimamente lugares públicos.

Nessa pesquisa, defendemos ainda que a atribuição de rótulos como clientelismo ou caudilhismo (termos que marcaram época na explicação das ações do governo de Leonel Brizola) não nos ajuda a avançar na compreensão do fato ${ }^{15}$. As ações tomadas pelos governantes municipais e

\footnotetext{
${ }^{15}$ Esses adjetivos aparecem nos trabalhos de Campilongo (1980) e Tedesco e Carini (2007).
} 
estaduais não se baseavam apenas em seu carisma ou no uso da máquina estatal a seu favor. A reforma agrária, naquele governo, pode ser caracterizada como uma política pública que teve como orientação clara transformar as condições de vida dos habitantes das áreas rurais do Rio Grande do Sul, como demonstram os documentos do governo estadual. Pensados nos termos de uma figuração, no sentido atribuído por Norbert Elias (1989 e 1987), Brizola, Calixto e Milton Serres Rodrigues foram indivíduos que estavam enredados em uma trama de dependências que nenhum deles foi capaz de direcionar sozinho. Havia o Master, os habitantes de Nonoai, as relações internas ao PTB e uma gama complexa de sujeitos em posições-chave.

É importante notar que a categoria "sem-terra" e as políticas públicas voltadas especificamente para ela se encerraram com o fim do governo de Leonel Brizola, ou seja, quando se desestrutura a figuração formada nos primeiros anos da década de $1960^{16}$. Mesmo que tenham ocorrido acampamentos durante o governo seguinte, seus resultados foram nulos em termos de novos assentamentos. Com o início do governo militar em abril de 1964, a categoria praticamente desaparece da vida social e das políticas de Estado, que irão privilegiar, daí por diante, o tema da "colonização"17.

Como procuramos demonstrar, ela somente voltará à cena política por ocasião da expulsão das famílias de colonos da Reserva Florestal de Nonoai. Naquele contexto, as relações de interdependência que marcavam a figuração que poderia ser pensada como estatal eram completamente distintas. Não havia ocupantes de cargos de governo envolvidos com as famílias expulsas ou com outras forças

\footnotetext{
${ }^{16}$ No final de 1962, o candidato ao governo do Estado do PTB, apoiado por Leonel Brizola, foi derrotado pelo ex-governador Ildo Meneghetti, que assumiu o cargo em 1963.

${ }^{17}$ Sobre os estudos dos processos de colonização durante o governo militar, ver o trabalho de Tavares dos Santos (1993).
} 
políticas organizadas. Naquele episódio, as relações entre os sujeitos que passaram a se identificar como "sem-terra" foram se construindo com as invasões de terras públicas. As invasões de áreas pertencentes ao Estado foram criando laços sociais com as figuras políticas do governador e de funcionários da própria burocracia que não se alinhavam por completo com o governo militar. Resolver a questão dos sem-terra foi, naquele momento, solucionar um problema criado pelo Estado com a regulamentação do uso das áreas indígenas, tanto do ponto de vista dos que ficaram sem um lugar para viver, como daqueles que administravam a máquina pública.

Havia, no sentido atribuído por Boltanski (2000), um conjunto de provas que permitira o reconhecimento da necessidade de intervenção estatal. Tais provas, de aceitação pública, demonstravam a situação de calamidade das famílias que haviam sido, do dia para noite, transformadas 222 em sem-terra e a existência concomitante de terras públicas (desapropriadas em 1962) subutilizadas. Isso permitiu a retomada da categoria "sem-terra" como um alvo de ação do Estado e de mobilização coletiva que levaria à formação do MST quase seis anos depois.

A passagem rápida pelos casos de movimentos dissidentes do MST no Estado de Pernambuco ajudou-nos a compreender melhor como, após 30 anos do surgimento da categoria "sem-terra", ela se institucionalizou como uma forma de negociação com os governos e não como identidade.

Se hoje ou há 40 anos saíssemos com um questionário nas áreas rurais e urbanas do Brasil e perguntássemos às pessoas sobre sua condição social, temos certeza de que poucos responderiam que eram sem-terra. Os casos que temos estudado no sul e no nordeste do Brasil mostram-nos que os moradores dessas áreas rurais se tornam sem-terra no momento em que tomam contato com os movimentos de sem-terra. Movimentos cuja principal propriedade não é 
representar uma parcela geral dos "pobres do campo", mas justamente desenvolver, na medida em que conseguem que o Estado e suas políticas avancem para áreas rurais, uma forma legítima de relação com Estado.

Um claro exemplo disso foi o crescente número de ocupações de terra ocorrido no país na década de 1990. Elas tiveram lugar, em sua grande maioria, após 1993, quando o Congresso Nacional aprovou os critérios para que uma terra fosse considerada improdutiva e, assim, estabeleceu quais áreas seriam passíveis de ser incluídas nos planos de reforma agrária. A partir desse ano, o número de ocupações de terra realizadas pelo MST multiplicou-se, tendo justamente por base o reconhecimento legal de que havia terras cuja finalidade econômica não vinha sendo cumprida. Ao mesmo tempo, o número de projetos de assentamento também aumentou.

Alguns dos trabalhos que mais se dedicaram a esse movimento, como Navarro (2008) e poucos outros, apresentam dificuldades de esboçar um quadro compreensivo sobre o MST justamente porque não realizam uma análise mais aprofundada do sentido da categoria social "semterra”. Tomam-na como uma "identidade", uma condição social natural do processo de desenvolvimento da sociedade brasileira, como na vasta obra de José de Souza Martins. Em ambos os casos, o sem-terra é visto como uma categoria moral: uma espécie de bom selvagem da ação coletiva. Com isso, cometem os mesmo erros de certas teorias sobre movimentos sociais que se focam no tema da identidade, ou ainda, da questão da injustiça ${ }^{18}$. Todas elas, por não pleitearem uma perspectiva sociológica em termos teóricos gerais (fora dos modelos de interpretação dos movimentos sociais e ações coletivas), tomam as ações do MST como expressão

\footnotetext{
${ }^{18}$ Para o caso brasileiro, a maior exceção a esses modelos naturalistas de descrição pode ser encontrada no trabalho de Boschi (1987).
} 
de agrupamentos identitários ou de interesses pré-constituídos que se volvem contra estruturas monolíticas.

Essas constatações permitem-nos entrar em diálogo com o que Tarrow (1999) designa como "estatismo dinâmico”, ou seja, uma teoria que reconhece a importância do Estado para a compreensão das ações coletivas, sem deixar de lado o fato de que nem tudo pode ser explicado pela mudança estrutural. Há, nessa perspectiva, um nível intermediário que visa equilibrar processos de curta e de longa duração, nos quais os movimentos sociais e as ações coletivas não são apenas objetos resultantes da força ou da fraqueza do Estado. Como o exemplo do Rio Grande do Sul nos mostra, eles se desenvolvem na medida em que as instituições governamentais se reforçam - como no caso dos vários órgãos que foram criados para cuidar de reforma agrária e colonização no Brasil das últimas décadas. Essas instituições, porém, são geridas em processos de curta duração e 224 dependem de disputas locais e pessoais entre agentes com poder de Estado - prefeitos e secretários, entre outros. No encontro histórico entre esses dois níveis, que são partes da mesma figuração, as cadeias de interdependências sofrem alterações, na medida em que os movimentos passam não apenas a se ajustar às oportunidades institucionais. Eles também aprendem os caminhos para criá-las e se tornam capazes, por meio das contentious conversations de que nos fala Tilly (1998), de transmitir suas táticas e formas de ação coletiva para outros sujeitos.

Se Tarrow (1999, p. 58) assinala que certas ações coletivas podem revelar as fraquezas do Estado e assim abrir sendas para o desenvolvimento de outras formas de protesto, nosso trabalho mostrou também que o mesmo pode ocorrer quando se revelam os pontos fortes de certos governos. Quando um determinado governo possui uma estrutura engendrada para lidar com movimentos de sem-terra, grupos e indivíduos envolvidos em outros processos históricos de 
reivindicação - como lutas sindicais, por exemplo - podem se orientar para essa forma de ação coletiva. O que tem sido visto na literatura sobre movimentos sociais e ações coletivas (especialmente em autores como Tarrow e Tilly) como uma luta pelo poder entre antagonistas, protagonizada entre movimentos sociais e Estado, pode ser entendido em nosso estudo como disputa colaborativa sem um lado necessariamente dominante. Por meio da criação de um vocabulário comum em torno da categoria "sem-terra" o Estado reconheceu a existência de uma nova força social no mundo rural e, talvez por isso, tenha também se tornado mais equipado para lidar com ela. Nutrindo-se dessa força, em princípio local, os movimentos foram ampliando seu escopo de reivindicações também para o âmbito nacional, o que permitiu sua expansão para além de suas áreas de origem e de identidade específica.

Nossa perspectiva, ao longo deste artigo, foi mostrar que não estávamos em um mundo dividido entre sem-terra de um lado, e "Estado" de outro, e que, em algum momento, os primeiros decidiram ou foram forçados a reclamar uma ação do segundo por meio de um movimento social. Afirmamos, aqui, que Estado e MST fazem parte de uma mesma figuração, cuja relação de interdependência se dá por meio da categoria "sem-terra", historicamente construída.

\section{Marcelo Carvalho Rosa}

é doutor em Sociologia, professor do Departamento de Sociologia da Universidade de Brasília e pesquisador do CNPq

\section{Referências bibliográficas}

AZEVEDO, F. A. 1982. As ligas camponesas. Rio de Janeiro: Paz e Terra. BASTOS, E. R. 1984. As ligas camponesas. Petrópolis: Vozes.

1985. "A mobilização camponesa no Nordeste - 1954/1964".

In: SANTOS, J. T. S. (org.). Revoluções camponesas na América Latina. Campinas: Unicamp/Ícone. 
BOLTANSKI, L. 2000. El amor y la justicia como competencias. Buenos Aires: Amorrortu Editores.

BOSCHI, R. 1987. A arte da associação: política de base e democracia no Brasil. Rio de Janeiro: Vértice.

CAMARGO, A. A. 1973. Brésil nord-est: mouvements paysans et crise populiste. Tese de Doutorado, Universidade de Paris.

CAMPILONGO, M. A. 1980. As relações sociopolíticas no Rio Grande do Sul: governo, partidos e sindicatos na conjuntura de 1958 a 1964. Dissertação de Mestrado, Departamento de Sociologia da Universidade Federal do Rio Grande do Sul.

CHAVES, C. A. 2000. A marcha nacional dos sem-terra: um estudo sobre a fabricação do social. Rio de Janeiro: Relume-Dumará.

ECKERT, C. 1984. Movimento dos agricultores sem-terra no Rio Grande do Sul: 1960-1964. Dissertação de Mestrado em Ciências de Desenvolvimento Agrícola. Programa de Pós-Graduação de Ciências Sociais em Desenvolvimento, Agricultura e Sociedade da Universidade Federal Rural do Rio de Janeiro - UFRRJ

ELIAS, N. 1987. La sociedad cortesana. Madrid: Fondo de Cultura Económica.

ELIAS, N. 1989. O processo civilizacional. Lisboa: Dom Quixote. vol. I.

226 FERNANDES, B. M. 2000. A formação do MST no Brasil. Petrópolis, RJ: Vozes.

MÉLIGA, L. D.; JANSON, M. D. C. 1982. Encruzilhada Natalino. Porto Alegre: Vozes.

NAVARRO, Z. 1996. "Democracia, cidadania e representação: os movimentos sociais rurais no estado do Rio Grande do Sul, Brasil, 1978-1990”. In: NAVARRO, Z. (org.). Política, protesto e cidadania no campo: as lutas sociais dos colonos e dos trabalhadores rurais no Rio Grande do Sul. Porto Alegre: Editora da Universidade.

. (org.). 1996. Política, protesto e cidadania no campo: as lutas sociais dos colonos e dos trabalhadores rurais no Rio Grande do Sul. Porto Alegre: Editora da Universidade.

2002. "Mobilização sem emancipação: as lutas sociais dos sem-terra no Brasil”. In: SANTOS, B. de S. (org.). Produzir para viver: os caminhos da produção não capitalista. Rio de Janeiro: Civilização Brasileira.

. 2008. “Nunca cruzaremos este rio - a estranha associação entre o poder do atraso, a história lenta e a 'Sociologia militante', e o ocaso da reforma agrária no Brasil". Texto apresentado no XXXII Encontro Anual da Anpocs. Caxambu, MG. 
PALMEIRA, M. 1979. "Desmobilização e conflito: relações entre trabalhadores e patrões na agroindústria pernambucana”. Revista de Cultura e Política, vol. 1, $\mathrm{n}^{\circ} 1$, agosto, pp. 41-55.

ROSA, M. 2004. O engenho dos movimentos: reforma agrária e significação social na zona canavieira de Pernambuco. Tese de Doutorado, Instituto Universitário de Pesquisas do Rio de Janeiro.

. 2006. "Uma região em movimento: as lutas por terra e a transformação das estruturas de poder e significação social na Mata pernambucana”. Revista Brasileira de Estudos Urbanos e Regionais (ANPUR), vol. 8, pp. 41-58.

2007. "Oligarquias agrárias, o Estado e o espírito do neoliberalismo no Brasil”. In: GRIMSON, A. (org.). Cultura y neoliberalismo. Buenos Aires: Clacso, pp. 111-125.

SANTOS, B. de S. (org.). 2002. Produzir para viver: os caminhos da produção não capitalista. Rio de Janeiro: Civilização Brasileira.

SANTOS, J. T. S. (org.). 1983. Revoluções camponesas na América Latina. Campinas: Unicamp/Ícone.

SIGAUD, L. 1979. Os clandestinos e os direitos. São Paulo: Duas Cidades. . 2000. "A forma acampamento: notas a partir da versão pernambucana”. Novos Estudos Cebrap, n 58, pp. 73-92.

.; ROSA, M.; MACEDO, M. E. 2008. “Ocupações de terra, acampamentos e demandas ao Estado: uma análise em perspectiva comparada”. Dados (Rio de Janeiro), vol. 51, pp. 107-142.

TARROW, S. 1999. "States and opportunities: the political structuring of social movements”. In: McADAM, D., McCARTHY, J.; ZALD, M. (orgs.). Comparative perspectives on social movements: political opportunities, mobilizing structures and cultural framings. Cambridge: Cambridge University Press.

TAVARES DOS SANTOS, J. V. 1993. Matuchos, exclusão e luta. Petrópolis, RJ: Vozes

TEDESCO, J. C.; CARINI, J. J. et al. 2006. "Populismo, nacionalismo e caudilhismo: a atuação do Master na Fazenda Sarandi - Norte do Rio Grande do Sul - 1960 a 1964". História: Debates e Tendências, n 6(1), pp. 63-99.

Porto Alegre: EST.

TILLY, C. 1998. “Contentious conversation”. Social Research, n 65, pp. 491-510. 


\title{
D)
}

\section{SEM-TERRA: OS SENTIDOS E AS TRANSFORMAÇÕES DE UMA CATEGORIA DE AÇÃO COLETIVA NO BRASIL}

\author{
MARCELO CARVALHO ROSA
}

Este artigo busca retomar as formas pelas quais a categoria social dos "sem-terra" se associou à ideia de movimento social no Brasil entre as décadas de 1960 e de 1980. Para isso, retoma-se dois contextos de investigação nos quais ela aparece. O primeiro é o governo Leonel Brizola, no Rio Grande do Sul, na década de 1960, e o segundo foram as ocupações ocorridas no mesmo Estado, entre 1978 e 1980, e que culminariam na formação do MST. Por meio desses casos procura-se demonstrar a imbricação entre as ações coletivas que envolvem os sem-terra e a atenção estatal que lhes foi atribuída em cada período. Defende-se a hipótese de que a mobilização dos sem-terra como categoria tem por suposto a mobilização do Estado nessas áreas.

Palavras-chave: Sem-terra; MST; Movimentos sociais rurais; Estado; Ocupação de terras.

\section{"SEM-TERRA": SENSES AND TRANSFORMATIONS OF A CATEGORY OF COLLECTIVE ACTION IN BRAZIL}

The article aims to analyze the forms the category "landless" has been linked to the agenda of social movements between the 60's and 80's in Brazil. It explores two distinct contexts in the Southern state of Rio Grande do Sul: the Leonel Brizola's administration from 1959 to 1963 and the land occupations occurred from 1978 to 1980 that led the process of MST (the Landless Workers Movement) formation. The main goal is to demonstrate the relation between those collective actions and the attention the State regarded to it in each period. As a mayor hypothesis it sustains that without the analysis of State mobilization we can not understand the sociological meaning of the landless in Brazil.

Keywords: Landless; MST; Rural social movements; State; Land occupations. 